\title{
Synthesis of Nitrogen Doped Carbon and Its Enhanced Electrochemical Activity towards Ascorbic Acid Electrooxidation
}

\author{
Sankararao Mutyala and Mathiyarasu Jayaraman \\ Electrodics and Electrocatalysis Division, CSIR-Central Electrochemical Research Institute, Karaikudi, Tamil Nadu 630 006, India \\ Correspondence should be addressed to Mathiyarasu Jayaraman; jmathiyarasu@gmail.com
}

Received 10 February 2014; Revised 21 May 2014; Accepted 30 May 2014; Published 26 June 2014

Academic Editor: Hamilton Varela

Copyright ( 2014 S. Mutyala and M. Jayaraman. This is an open access article distributed under the Creative Commons Attribution License, which permits unrestricted use, distribution, and reproduction in any medium, provided the original work is properly cited.

\begin{abstract}
Nitrogen doped carbon, synthesized by a novel way of carbonizing polyaniline in an inert atmosphere at a constant temperature of $800^{\circ} \mathrm{C}$, exhibits several unique features. The carbon: nitrogen ratio is found to increase with the treatment duration up to 120 minutes and a mass reduction of $60 \mathrm{wt} \%$ is observed with an interesting observation of the retention of the bulk polymer morphology, surprisingly, even after the carbonization process. The electrochemical activity evaluated with potassium hexacyanoferrate and hexamine ruthenium redox systems at a regular time interval helps to tune the catalytic activity. This type of nitrogen doped carbon prepared from polyaniline base exhibits excellent electrocatalytic activity as illustrated by the oxidation of ascorbic acid in neutral medium.
\end{abstract}

\section{Introduction}

Carbon is one of the prospective candidates in the field of electroanalysis mainly because of its broad potential window, very little background current, rich surface chemistry, chemical stability, and most importantly abundance [1]. A range of active carbon materials demonstrates requisite characteristics of a good catalyst support; however, they generally exhibit poor inherent catalytic activity for many technologically relevant reactions [2].

Previously, several methods have been used to alter the carbon support in an effort to improve its electrochemical reactivity. In addition to optimization of morphological properties, chemical modification of the carbon surface has been explored in order to enhance or tune the electrochemical activity of the carbon materials. Introduction of heteroatom such as oxygen, nitrogen, boron, sulfur, and halogen into the carbon matrix plays an important role in improving the catalytic performance [3]. For example, boron doping in carbon materials significantly improves the electrical conductivity and it is influenced by the boron doping level [4]. Sulfur doped amorphous carbon has been used as anode material for lithium ion batteries [5]. The added sulfur favorably increases the charge capacity and improves the electrochemical properties of the anode. However, the incorporated sulfur heteroatoms produce some side effects when they exist in unfavourable states.

Among the heteroatom's investigated, nitrogen doped carbon (NDC) has received significant attention as competitive oxygen reduction electrocatalysts. It is because nitrogen atom can donate the lone pair of electron to the carbon substrates more easily, which undergoes delocalization within the carbon material. Therefore, the adsorption properties as well as the electron transfer rate of the carbon during electrocatalytic processes may be enhanced significantly by $\mathrm{N}$-doping $[6,7]$.

In general, NDC has been prepared either by high temperature pyrolysis of precursor containing nitrogen and carbon [8-10] or by postannealing of various carbons in the presence of ammonia [11]. A number of $\mathrm{N}$-doped mesoporous carbons have been directly synthesized, using various $\mathrm{N}$-containing hydrocarbons (e.g., acetonitrile [12], polypyrrole $[13,14]$, or polyacrylonitrile $[15,16]$ ) as carbon precursors and mesostructured silica as hard templates. Ndoped mesoporous carbon spheres have also been successfully fabricated by using melamine formaldehyde as the precursor [17]. NDC materials have been synthesized using polyaniline-carbon composites that revealed electrocatalytic 
activity enhancement in oxygen reduction reaction [18]. Earlier attempts were reported $[19,20]$ in converting the polyaniline into nitrogen containing carbon. However, to our knowledge, there are no reports on the investigation of tuning the electrochemical activity of NDC materials. Thus, the extent of the electrocatalytic activity of these NDC and their application for other electrochemical reactions remain unknown.

In this work, we report a novel synthetic strategy for NDC that entails the carbonization of nitrogen containing polymeric material in a controlled environment to produce the nitrogen containing carbon materials. Typically, polyaniline was synthesized via a chemical oxidative polymerization and subjected to heat treatment in an inert atmosphere under a linear time intervals to modulate the composition. By this effort, the electrochemical activities of these NDCs could be optimized and improved to accomplish desired electrochemical activity.

\section{Experimental Methods}

2.1. Preparation of Polyaniline. Polyaniline (PANI) was synthesized based on the classical chemical oxidative polymerization of aniline. In a typical synthesis, $2.59 \mathrm{mg}$ of aniline hydrochloride and $5.71 \mathrm{~g}$ of ammonium peroxydisulfate were dissolved in $50 \mathrm{~mL}$ water in separate volumetric flasks. Both solutions were kept for an hour at room temperature, then mixed in a beaker, briefly stirred, and left to undergo polymerization. After 24 hours, PANI precipitate was subsequently collected on a Whatman filter paper and washed with three $100 \mathrm{~mL}$ portion of $0.2 \mathrm{M}$ hydrochloric acid and acetone. In this washing process, $0.2 \mathrm{M} \mathrm{HCl}$ removed all residual monomers followed by a final washing with acetone to remove low-molecular oligomers. This also prevented the formation of agglomerates of PANI during drying, to facilitate fine powder formation. The green polyaniline powder was dried in vacuum at $65^{\circ} \mathrm{C}$ and subjected to carbonization process.

2.2. Synthesis of NDC. PANI was carbonized in an inert atmosphere at $800^{\circ} \mathrm{C}$ systematically for various time intervals. Typically, $1.5 \mathrm{~g}$ of PANI in a silica boat was introduced in a tubular furnace. To produce inert atmosphere, high purity argon gas flow was maintained throughout the heat treatment process. The heat treated PANI; that is, NDCs obtained at different time intervals $30,60,90$, and 120 minutes were labelled as NDC-1, NDC-2, NDC-3, and NDC-4.

2.3. Electrode Preparation. In order to characterize these NDCs, they were made as carbon past electrodes, by mixing $6 \mathrm{mg}$ of the respective NDC powder with $20 \mu \mathrm{L}$ of paraffin oil and this ratio was maintained uniformly for the entire studies. The resulting paste was packed into the cavity electrodes (outer diameter $3 \mathrm{~mm}$ and inner diameter $1.6 \mathrm{~mm}$ ) and a brass rod was used for electrical contact. The electrode surface was made smooth and cleaned carefully with deionised water before the electrochemical measurements.
2.4. Characterization. Surface morphology of the carbonized PANI was analyzed using scanning electron microscopy (SEM) [VEGA3 TESCAN]. Raman spectra were recorded using high resolution dispersive Renishaw make Laser Raman spectrophotometer employing helium-neon excitation laser of maximum power density 2.0 watts $(633 \mathrm{~nm})$. Fourier transform-infrared (FTIR) vibration spectrum was taken by a Nexus 670 model FTIR spectrometer (make: Thermo Electron Corporation, USA). The wavelength region selected for taking the FTIR spectrum was $400-4000 \mathrm{~cm}^{-1}$. For taking the spectra of these synthesized materials, first it was mixed with high quality potassium bromide $(\mathrm{KBr})$ followed by making it as pellets and introducing it in the IR path and measurements are executed in transmission mode. The elemental composition (CHN) analysis was recorded using Elementar vario EL III, German. Thermal stability was characterized by thermogravimetric analysis (TGA) with model SDT Q600 V8.3 Build 101.

2.5. Electrochemical Measurements. Electrochemical measurements were performed using a potentiostat, Autolab model PGSTAT-30, in a conventional three-electrode configuration, with nitrogen containing carbon paste as the working electrode and a platinum and $\mathrm{Ag} / \mathrm{AgCl}$ electrode as counter and reference electrodes, respectively. Cyclic voltammetry was carried out in a solution containing $0.01 \mathrm{M}$ of potassium ferricyanide + potassium ferrocyanide in $0.1 \mathrm{M}$ potassium nitrate solution at room temperature $\left(25 \pm 1^{\circ} \mathrm{C}\right)$. Impedance measurements were performed in a similar electrochemical cell using Ivium Technologies, Compactstat Electrochemical analyzer in $0.01 \mathrm{M}$ potassium ferricyanide + potassium ferrocyanide in $0.1 \mathrm{M}$ potassium nitrate solution by applying an alternating voltage of $5 \mathrm{mV}$ in a frequency range from $0.01 \mathrm{~Hz}$ to $100 \mathrm{kHz}$ using THALES 4.13 software. All the solutions were prepared in fresh Millipore water of resistivity $18.2 \mathrm{M} \Omega \cdot \mathrm{cm}$.

\section{Result and Discussion}

3.1. Elemental Analysis. Table 1 shows the elemental analysis of PANI and pyrolyzed PANI that reflects the varying amount of carbon and nitrogen depending on the treatment duration at $800^{\circ} \mathrm{C}$. As expected, the carbon content increases to a value of $70 \%$ on heat treatment in NDC-2 and NDC-3 samples. However, any further increase in treatment duration results in a decrease in carbon content perhaps due to the expected decomposition of the carbon structure. This can be further confirmed by observing the nitrogen content, where it decreases from a value of $11 \%$ to $6.5 \%$. Decomposition is clearly reflected in the $\mathrm{C} / \mathrm{N}$ ratio that interestingly increases to a moderate value of 10.5. During the carbonization of PANI, it is possible that phenazine-like cross-linked units [21] are formed by the cross-linking of PANI chains accounting for the $71 \%$ of carbon and $12 \%$ nitrogen (leading to a $\mathrm{C} / \mathrm{N}$ ratio of $\sim 6.0$ ), as is proved by the spectral analysis reported below. Prolonged heat treatment, nevertheless, leads to the decomposition of the phenazine like carbon structure facilitating a decrease in carbon and nitrogen content as observed and 
<smiles>CNc1ccc(Nc2ccc(Nc3ccc(Nc4ccc(Nc5ccc(Nc6ccc(N)cc6)cc5)cc4)cc3)cc2)cc1</smiles>

Polyaniline

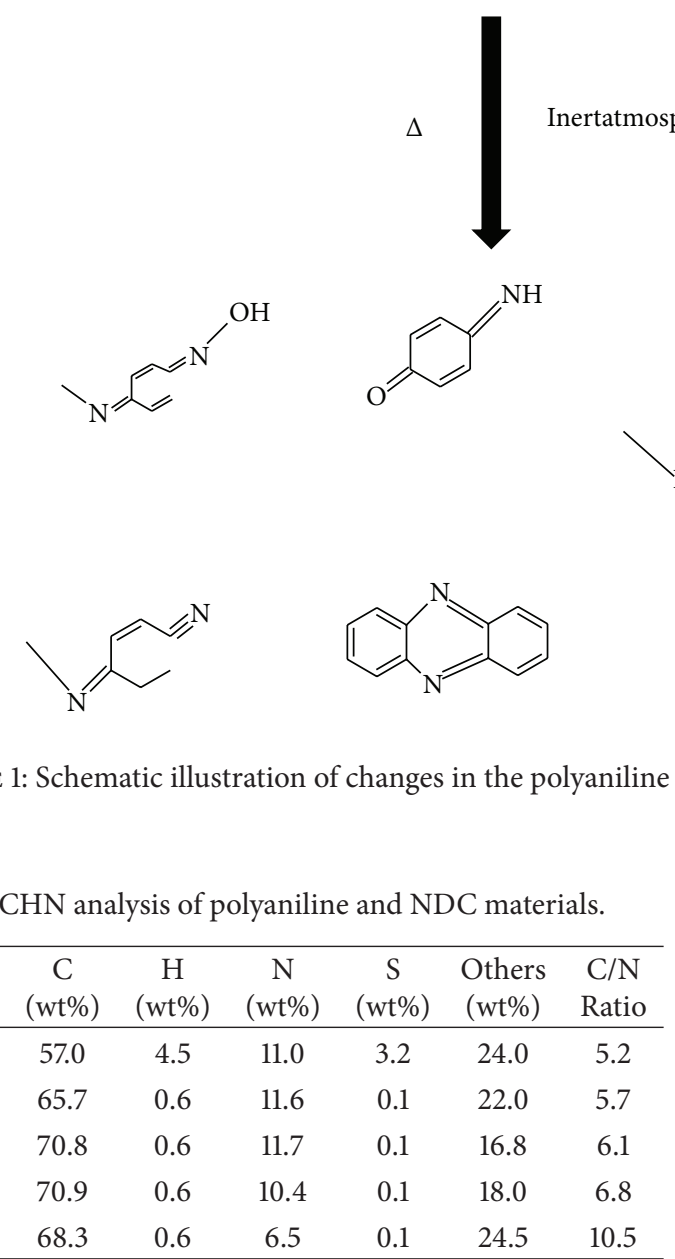

these expected processes are proposed in Figure 1. Depending on the experimental conditions, the samples can always contain some oxygen, chlorine, and sulphur [22] and during the heat treatment their content decreases.

3.2. FITR Analysis. Figure 2 shows a comparison of FTIR spectra of these materials in the range of $400-4000 \mathrm{~cm}^{-1}$. The characteristic band of PANI appears at $1565 \mathrm{~cm}^{-1}$ corresponding to the benzenoid and quinoid rings and the band at $1482 \mathrm{~cm}^{-1}$ is attributed to the $\mathrm{C}=\mathrm{C}$ aromatic ring stretching vibration. The $1296 \mathrm{~cm}^{-1}$ band is assigned to $\mathrm{C}-\mathrm{N}$ vibrational stretching of a secondary aromatic amine, whereas the peak at about $1115 \mathrm{~cm}^{-1}$ corresponds to aromatic $\mathrm{C}-\mathrm{H}$ in-plane bending mode. The $\mathrm{C}-\mathrm{H}$ out-of-plane deformations of the 1,4 -disubstituted rings are located in the region of $804 \mathrm{~cm}^{-1}$. The band at $503 \mathrm{~cm}^{-1}$ is related to the out-of-plane $\mathrm{C}-\mathrm{H}$ wagging vibrations. In general, the region $2500-4000 \mathrm{~cm}^{-1}$ of the spectra strongly reflects the hydrogen bonding. This can be attributed to $\mathrm{H}$-bond formation between the $-\mathrm{N}-\mathrm{H}$ and $=\mathrm{N}-\mathrm{H}$ groups in adjacent polymer chains while the band at $3627 \mathrm{~cm}^{-1}$ is assigned to the overtone band of nitrogen atoms in PANI.

After carbonization, however, most of the peaks disappear along with the emergence of many new peaks indicating structural changes as shown in the schematics (Figure 1). After 30 minutes of carbonization (NDC-1), a decrease in intensity of the band at $3307 \mathrm{~cm}^{-1}$ is observed, ascribed to amine stretching $(\mathrm{N}-\mathrm{H})$ vibration. It is due to the reduction in the number of hydrogen connected to the nitrogen atoms in PANI [23]. Further, the two main peaks at $1573 \mathrm{~cm}^{-1}$ and $1232 \mathrm{~cm}^{-1}$ have been broadened and shifted, perhaps due to the cross-linking of the polymeric rings reflecting the formation of phenazine type rings. As the treatment time increases, a new band appears at $2996 \mathrm{~cm}^{-1}$ corresponding to the $\mathrm{C}-\mathrm{H}$ aromatic stretching vibration. The broader region observed in the case NDC-2 reveals a loss of residual water in the sample. The absorption band about $1743 \mathrm{~cm}^{-1}$ in NDC-3 clearly indicates the presence of $\mathrm{C}=\mathrm{O}$ group. This is reasoned as the structural changes followed by the formation of oximelike moiety. The appearance of peaks at $2209 \mathrm{~cm}^{-1}$ and $2212 \mathrm{~cm}^{-1}$ in NDC-1 and NDC-3 may be attributed to cumulated stretching vibration of the $\mathrm{N}=\mathrm{C}=\mathrm{O}$ or the nitrile group. The peak at $806 \mathrm{~cm}^{-1}$ in NDC-3 reflects the N-H out-ofplane wagging and twisting vibration. The band at $1213 \mathrm{~cm}^{-1}$ in NDC- 4 corresponds to $\mathrm{sp}^{2} / \mathrm{sp}^{3} \mathrm{C}-\mathrm{C}$ vibrations. The peak 

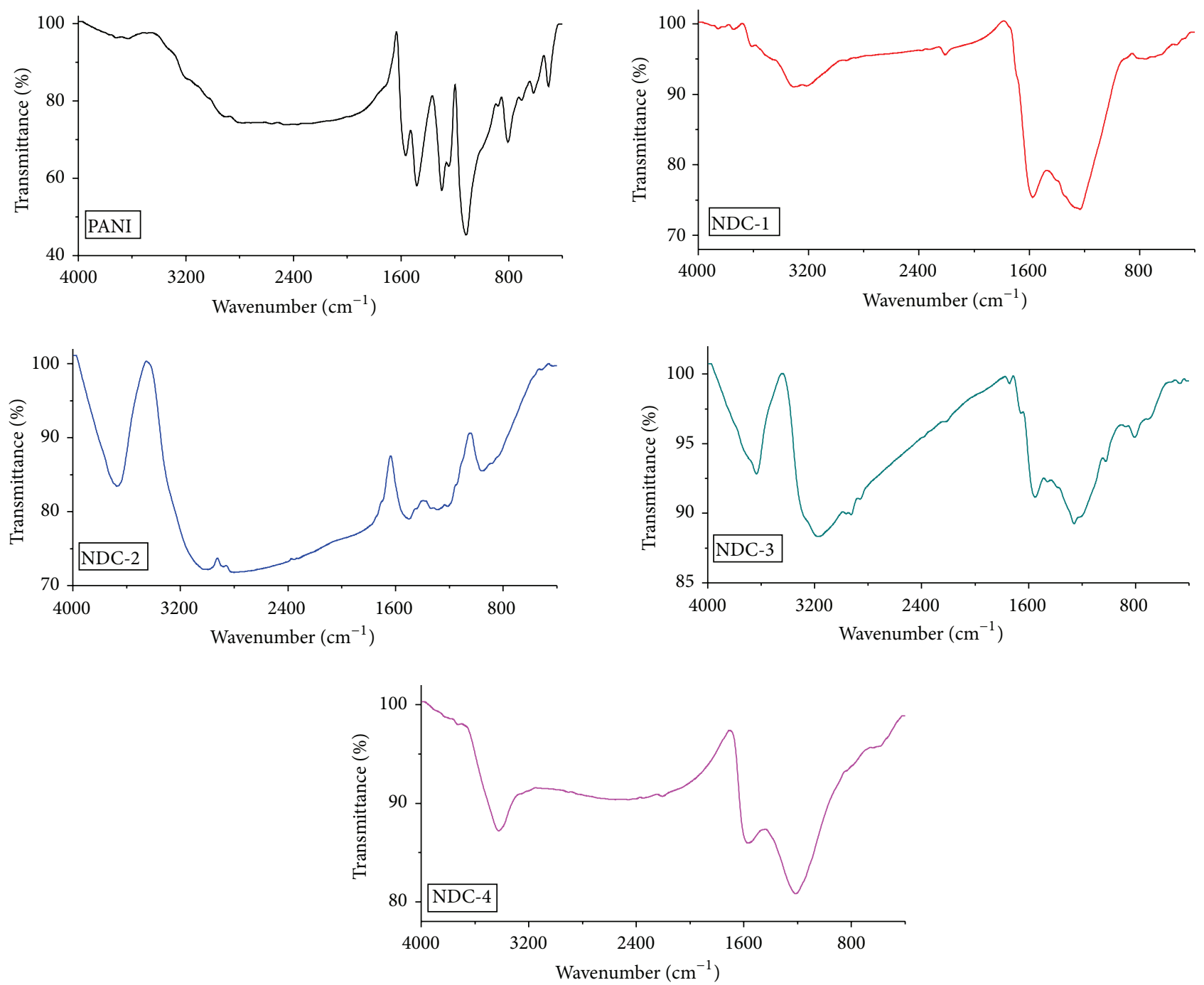

FIgURE 2: FTIR spectra of PANI and heat treated PANI such as NDC-1, NDC-2, NDC-3, and NDC-4 exposed to systematic time intervals $30,60,90$, and 120 minutes, respectively, in an inert atmosphere at $800^{\circ} \mathrm{C}$.

at $949 \mathrm{~cm}^{-1}$ observed in NDC-2 supports the presence of oxime-like structures in the sample. It is interesting to note that the $\mathrm{C}-\mathrm{N}$ asymmetric stretching vibration at $1296 \mathrm{~cm}^{-1}$ (PANI) is shifted to 1288 (NDC-2); $1260 \mathrm{~cm}^{-1}$ (NDC-3) is due to the change in bond length between nitrogen and carbon atom. After carbonization process, the peaks at 1573, 1501, 1550 , and $1568 \mathrm{~cm}^{-1}$ in NDC-1, NDC-2, NDC-3, and NDC4 indicate the aromatic $\mathrm{C}=\mathrm{C}$ vibrational stretching with $\mathrm{sp}^{2}$ configuration rather than olefinic one. In the case of NDC4 , the characteristic peak at $2459 \mathrm{~cm}^{-1}$ corresponds to multiple bonds resulting in overtone bands of respective nitrogen containing carbonaceous materials. These observations clearly indicate that nitrogen (heteroatom) incorporation is successful in carbonaceous materials as shown in Figure 2.

3.3. Raman Spectroscopy Analysis. Raman spectroscopy is a widely used method for analyzing different carbonaceous materials particularly to distinguish various types of bonds between carbon atoms. Accordingly, Figure 3 shows the Raman spectrum of PANI and NDC materials. From the spectra, it is observed that the simple PANI spectrum is transformed to a pattern represented by two peaks at 1582 and $1348 \mathrm{~cm}^{-1}$, corresponding to the "so-called" graphitic $(\mathrm{G})$ and disordered (D) band parts, respectively. In the case of NDC (heat treated PANI), the position of the two main bands results from PANI by two steps: (i) loss of protonating acid in the first step, which is followed by the (ii) formation of phenazine-like cross-linked units during the carbonization process which is supported by the elemental and FTIR analysis. During the heat treatment of PANI, the abovementioned bands appear at dissimilar intensities followed by a refinement of the $D$ and $G$ bands in a systematic time interval. On careful examination of relative integrated intensity ratio $\left(I_{\mathrm{D}} / I_{\mathrm{G}}\right)$, it is found to decrease corresponding to the number and/or size of graphitic micro domains, and therefore an increase in the number of fourfold coordinated 


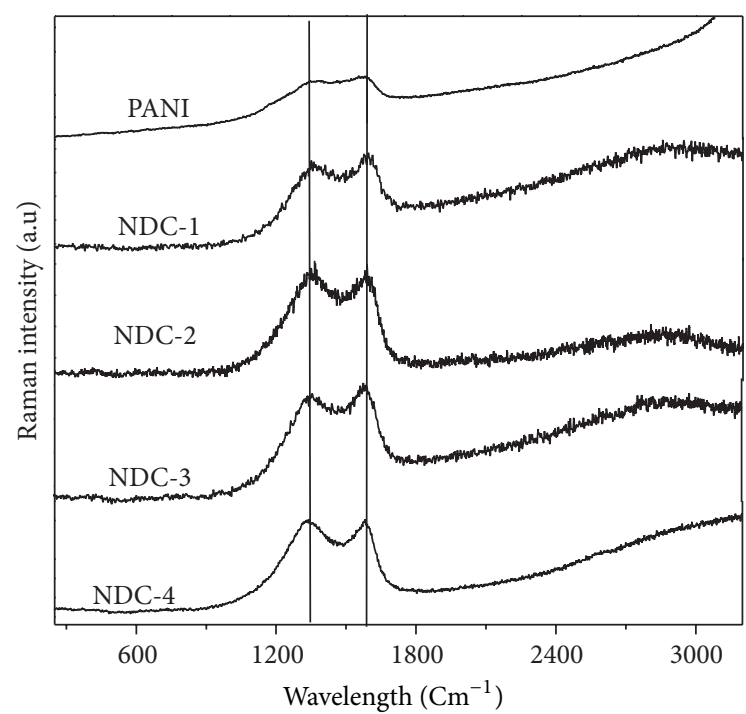

FIGURE 3: Laser Raman spectra of PANI and heat treated PANI such as NDC-1, NDC-2, NDC-3, and NDC-4 exposed to systematic time intervals $30,60,90$, and 120 minutes, respectively, in an inert atmosphere at $800^{\circ} \mathrm{C}$. Excitation wavelength is $633 \mathrm{~nm}$.

carbon atoms $\left(\mathrm{sp}^{3} / \mathrm{sp}^{2}\right)$ is ascertained. The peak position and peak intensity slightly change from one material to another perhaps due to the structural disorder in the matrix. The $I_{\mathrm{D}} / I_{\mathrm{G}}$ ratio of synthesized PANI, NDC-1, NDC-2, NDC3 , and NDC-4 was calculated using Raman intensity and the values are found to be $0.9,0.92,0.96,0.98$, and 0.99 , respectively. The increases in $I_{\mathrm{D}} / I_{\mathrm{G}}$ ratio after heat treatment clearly confirm the graphitization of polyaniline leading to successful carbonization process.

3.4. Surface Morphology Analysis. The surface morphology of the carbonized PANI is examined using scanning electron microscopy (SEM). Accordingly, Figure 4 shows typical morphological features of both PANI and NDC. When it is viewed from an angle perpendicular to the surface at a low magnification, it appears to contain white spots all across the surface. This clearly indicates the surface roughness of the matrix associated with a granularity of the conductive materials. The SEM images (Figure 4) further indicate that the synthesized PANI morphology is conserved even after the carbonization process, as observed by many researchers [2429]. Thus, the retention of morphology is observed with a small shrinkage in size of the particle in NDC-2. Further close observation reveals small defects at the edges of the particles.

3.5. Thermal Stability Analysis. TGA analysis is performed to investigate the thermal stability of the materials and Figure 5 shows the TGA curves of both PANI and NDC. All materials exhibit considerable amount of mass reduction below $100^{\circ} \mathrm{C}$, perhaps due to the loss of absorbed water molecules or trapped hydrogen chloride. However, above $200^{\circ} \mathrm{C}$, major mass reduction takes place illustrating the superior thermal stability of NDC compared to that of PANI base. This is due to faster degradation of the small chains of PANI base. In the case of NDC, significant weight loss occurs between 450 and $850^{\circ} \mathrm{C}$ owing to the oxidative decomposition of polymer chains followed by incorporation of the nitrogen atom [30]. The stability of the NDC increases with the heat treatment duration and thus NDC- 4 shows maximum thermal stability. These results confirm that the weight loss of the carbonized material increases with temperature. Above $800^{\circ} \mathrm{C}$ all these materials, interestingly, result in complete degradation (i.e., nearly zero mass) which indicates the formation of metalfree NDC by this process. In contrast, most of the processes pertain to carbonaceous material preparation; incorporation of metal impurities is implicit [31].

3.6. Cyclic Voltammetric Studies. Electrochemical activity of NDC (carbonized polyaniline) has been examined using cyclic voltammetry with the help of standard redox systems such as potassium hexacyanoferrate $\left[\mathrm{Fe}(\mathrm{CN})_{6}\right]^{3-/ 4-}$. The response observed in terms of difference in cathodic and anodic peak potential $\left(\Delta E_{\mathrm{p}}=E_{\mathrm{p}, \mathrm{a}}-E_{\mathrm{p}, \mathrm{c}}\right)$ and the performance is discussed in terms of $\Delta E_{\mathrm{p}}$ values (for an ideal system it should be $59 / n \mathrm{mV}$ at $25^{\circ} \mathrm{C}$, where $n$ is the number of electrons involved in the redox reaction). The $\left[\mathrm{Fe}(\mathrm{CN})_{6}\right]^{3-/ 4-}$ is an outer sphere redox system that depends strongly on the surface heterogeneity of the carbon matrix. The other outer sphere redox system hexaammineruthenium (III) $\left[\mathrm{Ru}\left(\mathrm{NH}_{3}\right)_{6}\right]^{3+/ 2+}$ that has very minimal surface dependence on particular surface sites or functional groups is also employed as the redox system for activity assessment.

Figure 6 shows the cyclic voltammogram behaviour of polyaniline and various NDC electrodes in $0.01 \mathrm{M}$ potassium ferricyanide and hexaammineruthenium (III) in $0.1 \mathrm{M}$ potassium nitrate solution. In general, all cyclic voltammograms exhibit similar current-potential profiles in these redox systems except PANI in Figures 6(a) and 6(f) and NDC-1 in Figures 6(b) and 6(g); these are suggesting that the surface conditions of the modified electrode are almost similar. Interestingly, PANI modified paste electrode shows a capacitive loop and the poor conductivity of PANI is explained due to the presence of leucoemeraldine or pernigraniline form. In the case of NDC-1, the electrode surface just reflects an insulating behaviour of the material and it is understandable that 30 minutes of treatment is not sufficient to fully convert PANI into a conductive carbonised form. Other NDCs show a good redox activity and the peak-potential separation for those electrodes is given in Table 2.

Except NDC-1, all other NDCs exhibit clear redox behaviour with better peak-to-peak separation $\left(\Delta E_{\mathrm{p}}\right)$ values. For other NDCs, the peak-to-peak separation is observed in between 100 and $150 \mathrm{mV}$ and cathodic/anodic peak current ratios $\left(I_{\mathrm{a}} / I_{\mathrm{c}}\right)$ are close to one. It is reported that the introduction of nitrogen heteroatom in the carbon structure improves the electroactivity of the materials since the nitrogen containing lone pair of electrons undergoes delocalization within the carbon material [31-34]. This lone pair of electrons is responsible for the enhanced electrochemical activity of the NDCs. The surface in-homogeneity of the NDCs in terms of microstructural characteristics/surface functionalization is 

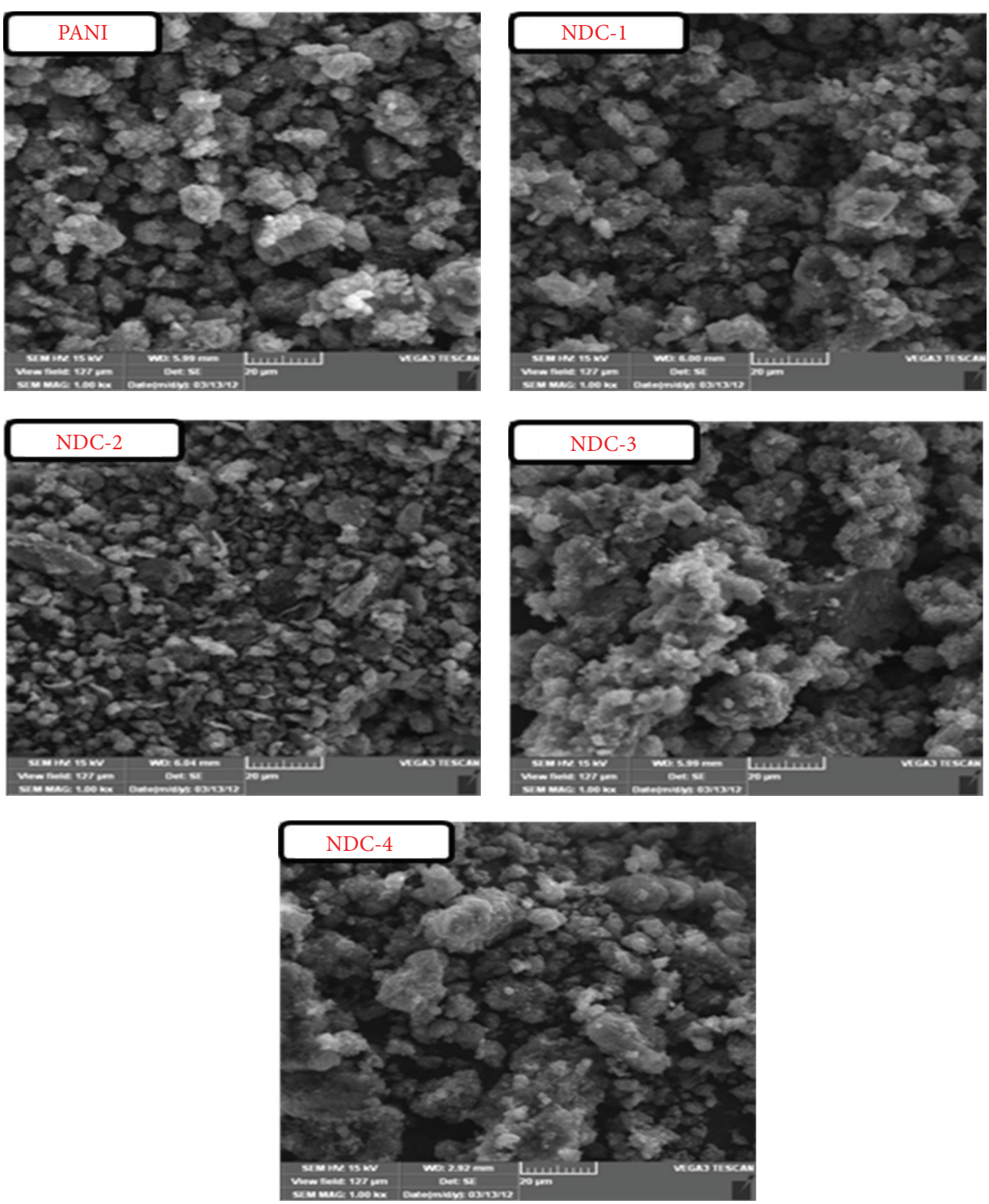

FIgURE 4: Scanning electron microscopy (SEM) micrographs of PANI and heat treated PANI such as NDC-1, NDC-2, NDC-3, and NDC-4 exposed to systematic time intervals $30,60,90$, and 120 minutes, respectively, in an inert atmosphere at $800^{\circ} \mathrm{C}$.

TABLE 2: Peak-to-peak separation obtained from cyclic voltammograms of respective redox systems.

\begin{tabular}{lcc}
\hline Electrode & \multicolumn{3}{c}{$\Delta E_{\mathrm{p}}, \mathrm{mV}$} \\
& {$\left[\mathrm{Fe}(\mathrm{CN})_{6}\right]^{3-/ 4-}$} & {$\left[\mathrm{Ru}\left(\mathrm{NH}_{3}\right)_{6}\right]^{3+/ 2+}$} \\
\hline NDC-1 & - & - \\
NDC-2 & 150 & 141 \\
NDC-3 & 140 & 120 \\
NDC-4 & 130 & 100 \\
Polyaniline & - & - \\
\hline
\end{tabular}

evidenced by the slight increase in the $\Delta E_{\mathrm{p}}$ values $(10-20 \mathrm{mV})$ of $\left[\mathrm{Fe}(\mathrm{CN})_{6}\right]^{3-/ 4-}$ redox system.

Table 2 results are indicative of the electrocatalytic activity for the $\left[\mathrm{Fe}(\mathrm{CN})_{6}\right]^{3-/ 4-} /\left[\mathrm{Ru}\left(\mathrm{NH}_{3}\right)_{6}\right]^{3+/ 2+}$ redox reaction, as clearly evidenced by significant peak-potential separation and high peak current $\left(i_{\mathrm{pa}}, i_{\mathrm{pc}}\right)$ for these electrodes. These results indicate that the NDC- 4 carbon shows better electrocatalytic activity for the $\left[\mathrm{Fe}(\mathrm{CN})_{6}\right]^{3-/ 4-} /\left[\mathrm{Ru}\left(\mathrm{NH}_{3}\right)_{6}\right]^{3+/ 2+}$ redox reaction compared to other NDC carbon paste electrodes. The peak current densities for the NDC-3 and NDC4 are higher than that of other electrodes, which might be owing to the high surface roughness and hence a higher effective surface area.

3.7. Electrochemical Impedance Spectroscopy (EIS) Studies. Electrochemical impedance spectroscopy is performed to investigate the activity of the PANI and NDC using freely diffusing and negatively charged redox species. The corresponding Nyquist complex plane impedance plots of the electrodes are shown in Figure 7. The preparation procedure, 


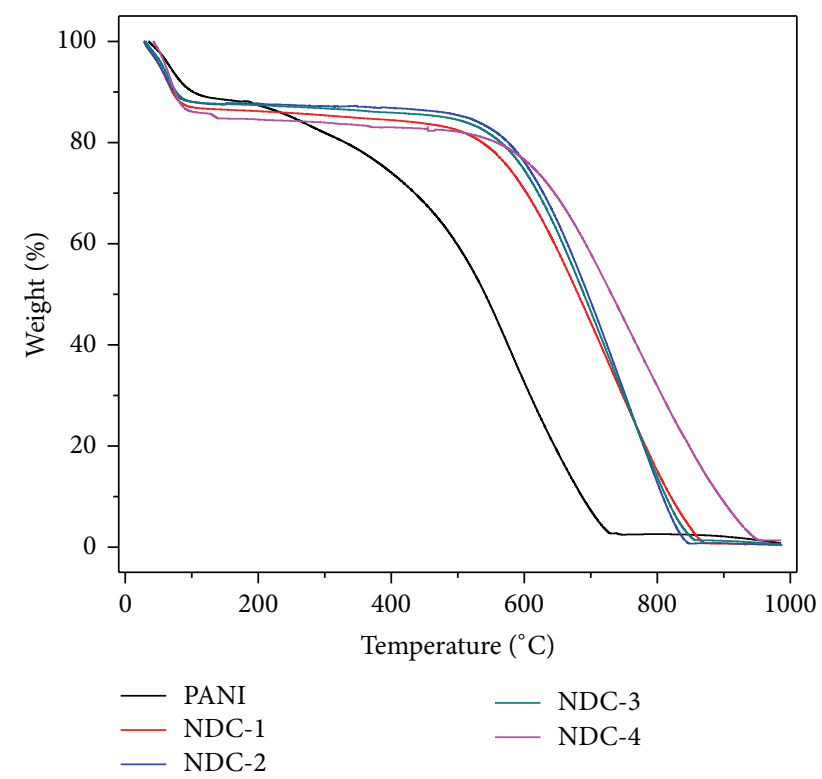

Figure 5: Thermogravimetric analysis (TGA) of PANI and heat treated PANI such as NDC-1, NDC-2, NDC-3, and NDC-4 exposed to systematic time intervals $30,60,90$, and 120 minutes, respectively, in an inert atmosphere at $800^{\circ} \mathrm{C}$.

carbonization process, and the heat treatment temperatures had a profound influence on the impedance spectra. The impedance spectrum of PANI exhibits only diffusion processes and all other NDC materials show a charge transfer process followed by diffusion. Further, all NDCs exhibit similar impedance behaviour except NDC-1, where the close observation does not show a perfect Nyquist behaviour (semicircle) that can be attributed to the incomplete nitrogen doping and high residual particles. In a comparison, the NDCs exhibit a depressed semicircle in the high frequency region followed by a straight line with a slope of nearly $45^{\circ}$ in the low frequency region, which is typical of a porous film coated on metals in the asymmetric metal/film/electrolyte configuration [35]. The depressed semicircle in the high frequency region could be ascribed to the charge (electron and proton) exchange at the carbon electrode/electrolyte interface. A straight line at low frequencies can be explained using a Warburg diffusion element due to the semi-infinite diffusion of ions at the carbon electrode/electrolyte interface [36]. Thus, an equivalent circuit model is employed in this study to represent the impedance behaviour of the porous electrode at the open circuit potential and it is portrayed in Figure 8.

In this circuit, $R_{\mathrm{s}}$ represents the solution resistance; $R_{1}$ and $R_{2}$ are the charge transfer resistance $R_{\mathrm{ct}} . Q_{1}$ and $Q_{2}$ are the double layer capacitance expressed as $C_{\mathrm{dl}}$. The fitted results according to the equivalent circuit are also shown in Figure 8. The good fit implies that the equivalent circuit models can reasonably explain the electrochemical processes at the interface of the carbon supports/electrolytes at open circuit potential. Kinetic parameters calculated from the Nyquist plot are listed in Table 3. A comparison of the EIS Nyquist
TABLE 3: Charge transfer resistance $\left(R_{\mathrm{ct}}\right)$, double layer capacitance $\left(C_{\mathrm{dl}}\right)$, and exchange current $\left(i_{0}\right)$ for various NDC electrodes in $0.01 \mathrm{M}\left[\mathrm{Fe}(\mathrm{CN})_{6}\right]^{3-/ 4-}+0.1 \mathrm{M} \mathrm{KNO}_{3}$ solution at the open circuit potential. The kinetic parameters have been calculated using the Randles equivalent circuit shown in Figure 8.

\begin{tabular}{lccc}
\hline Electrode & $R_{\mathrm{ct}}(\Omega)$ & $C_{\mathrm{dl}}(\mu \mathrm{F})$ & $i_{0}\left(\mathrm{~mA} \mathrm{~cm}^{-2}\right)$ \\
\hline Polyaniline & - & - & - \\
NDC-1 & 508 & 23 & $2.34 \times 10^{-3}$ \\
NDC-2 & 450 & 240 & $2.64 \times 10^{-3}$ \\
NDC-3 & 317 & 537 & $3.70 \times 10^{-3}$ \\
NDC-4 & 310 & 519 & $3.83 \times 10^{-3}$ \\
GCE & 200 & 0.07 & $1.83 \times 10^{-3}$ \\
\hline
\end{tabular}

plots shows that the size of the semicircle drastically decreases with varying nitrogen content in the NDC electrode closer to the conventional glassy carbon electrode, and this can be ascribed to the doping of nitrogen atoms. For the PANI electrode, the impedance does not accord with the trend observed as it behaves like a highly resistive matrix. The distorted semicircle behaviour of NDC-1 in the high frequency region is due to the porous nature of the matrix which can be attributed to incomplete carbonization. A comparison of the charge transfer resistance among various NDCs with that on conventional glassy carbon electrode (GCE) reveals the ease of charge (electron) transfer across the interface of the NDC paste electrode/electrolyte. In particular, the NDC-4, prepared with a heat treatment at $800^{\circ} \mathrm{C}$ for 120 minutes, shows lowest nitrogen content with the smallest $R_{\mathrm{ct}}$ (highest value of exchange current $i_{0}$ ) suggesting that the electrochemical activity of the sample is superior compared to that of other electrodes.

3.8. Electrochemical Oxidation of Ascorbic Acid. During this investigation, it is observed that the NDC prepared from the PANI base exhibits excellent electrochemical activity. The activity enhancement is reasoned as the nitrogen atom doped in the carbon network containing the lone pair of electron that undergoes delocalization which is responsible for the improved conductivity. In an effort to portray the catalytic activity, the best performed material, that is, NDC4, has been utilized as the electrode material for ascorbic acid oxidation. Ascorbic acid is an important molecule in biological systems and extensive research has been in progress to develop voltammetric methods for its estimation [37-39]. However, because of its high overpotential, poor reproducibility, low selectivity, and poor sensitivity on the conventional electrodes, it is difficult to determine ascorbic acid by direct oxidation in a neutral medium.

Figure 9 shows a comparison of the cyclic voltammogram of $10 \mathrm{mM}$ ascorbic acid using Vulcan carbon (without $\mathrm{N}$ doping) and NDC paste electrodes as working electrodes. Ascorbic acid shows a sluggish response in the form of an oxidative wave at $0.30 \mathrm{~V}$ on pure carbon electrode, while the nitrogen doped electrode leads to a significant negative shift of oxidation potential $\left(E_{\mathrm{p}}=0.22 \mathrm{~V}\right)$ along with a concomitant enhancement in the peak current density confirming better 


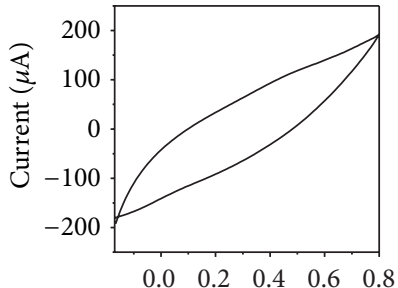

Potential $V$ versus $\mathrm{Ag} / \mathrm{AgCl}$

(a)

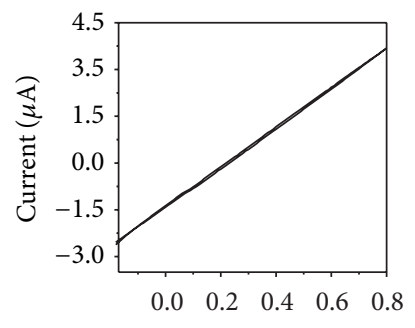

Potential $V$ versus $\mathrm{Ag} / \mathrm{AgCl}$

(b)

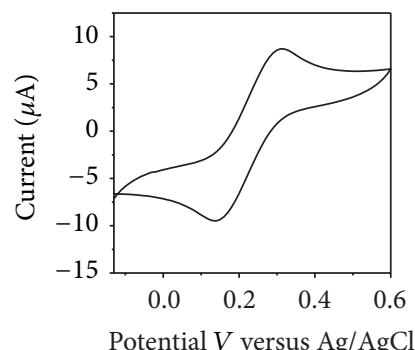

(c)

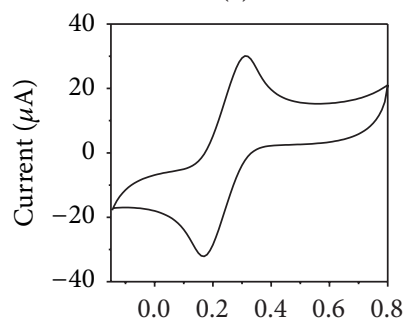

Potential $V$ versus $\mathrm{Ag} / \mathrm{AgCl}$

(d)

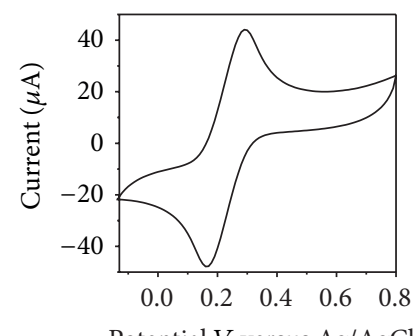

Potential $V$ versus $\mathrm{Ag} / \mathrm{AgCl}$

(e)

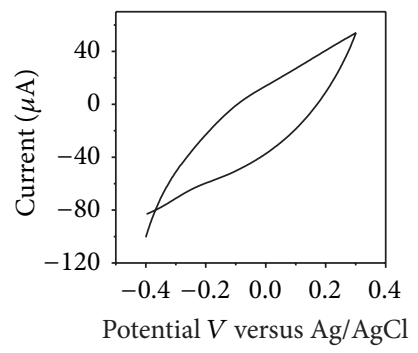

(f)

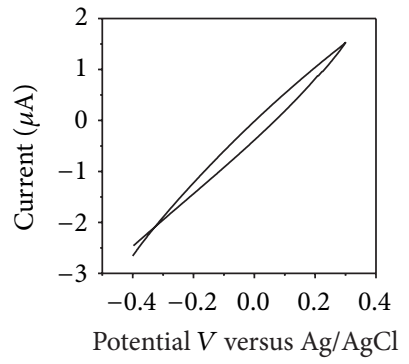

(g)

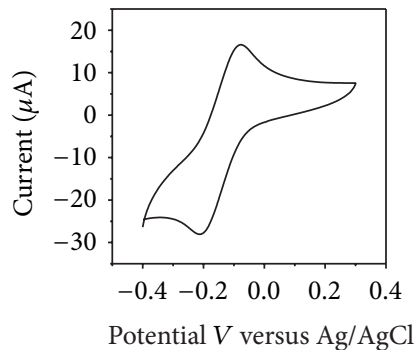

(h)

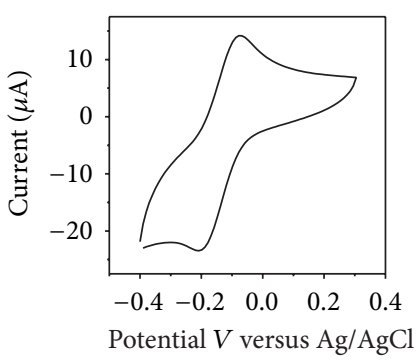

(i)

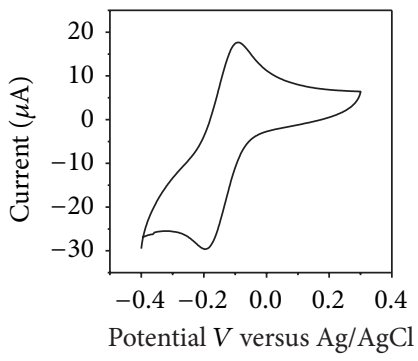

(j)

FIGURE 6: Cyclic voltammograms of different NDC materials: ((a)-(e)) represent the PANI, NDC-1, NDC-2, NDC-3, and NDC-4 in 0.01 M potassium ferricyanide $+0.1 \mathrm{M}$ potassium nitrate solution and ((f)-(j)) represent the PANI, NDC-1, NDC-2, NDC-3, and NDC-4 in 0.01 M of hexaammineruthenium (III) + $0.1 \mathrm{M}$ potassium nitrate solution. Scan rate is $20 \mathrm{mVs}^{-1}$. 

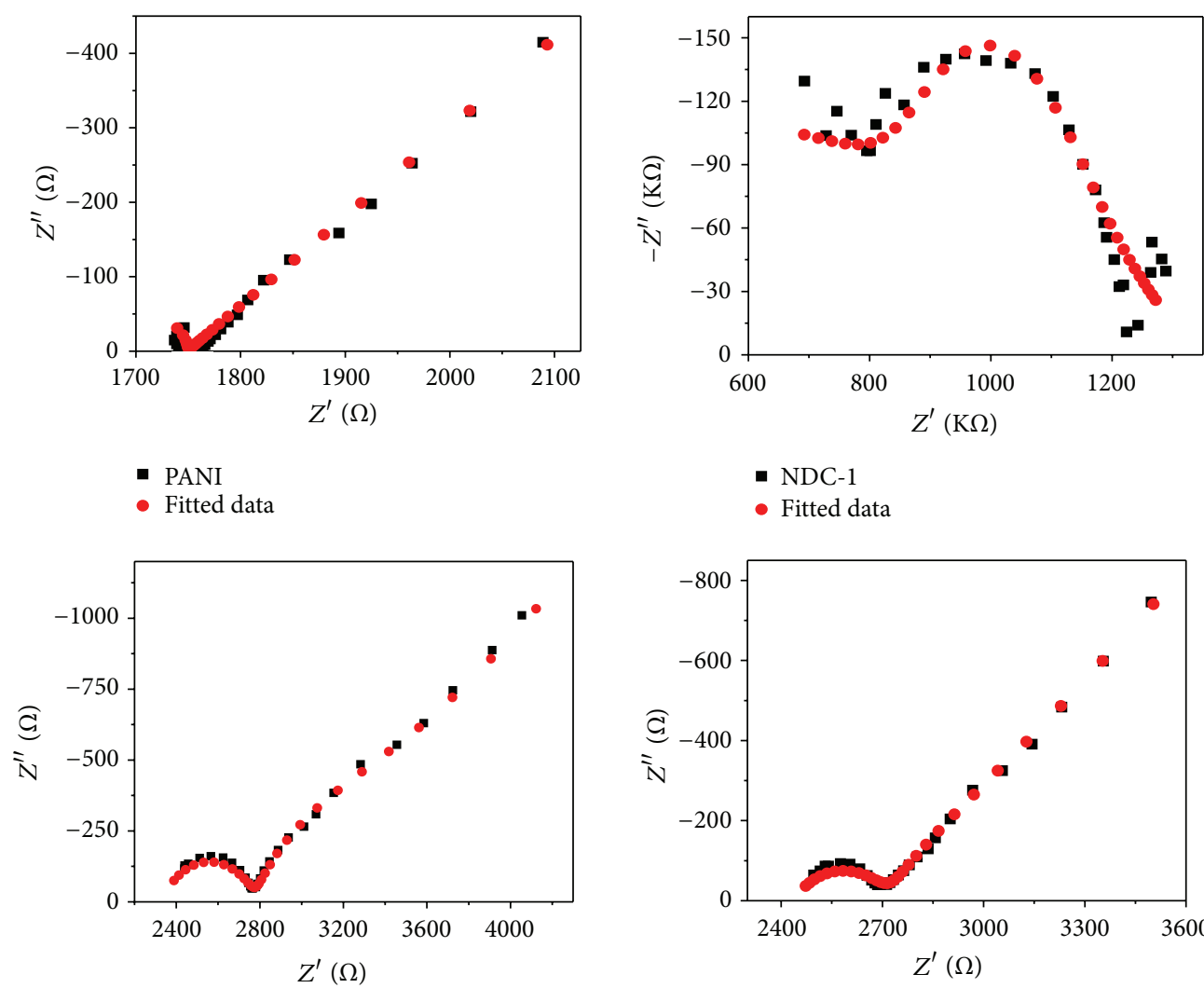

- NDC-1

- Fitted data

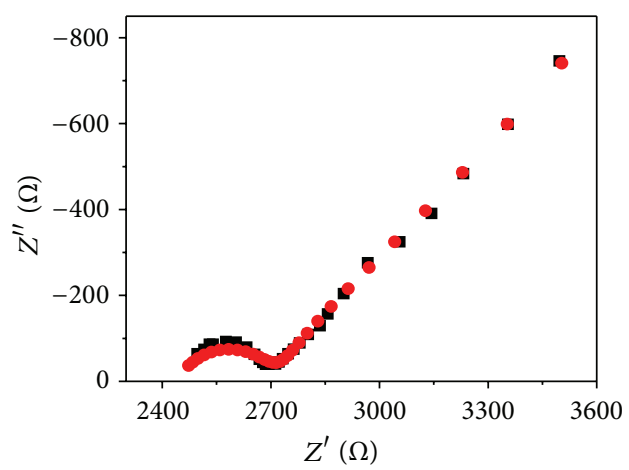

- NDC-2

- Fitted data

- NDC-3

- Fitted data
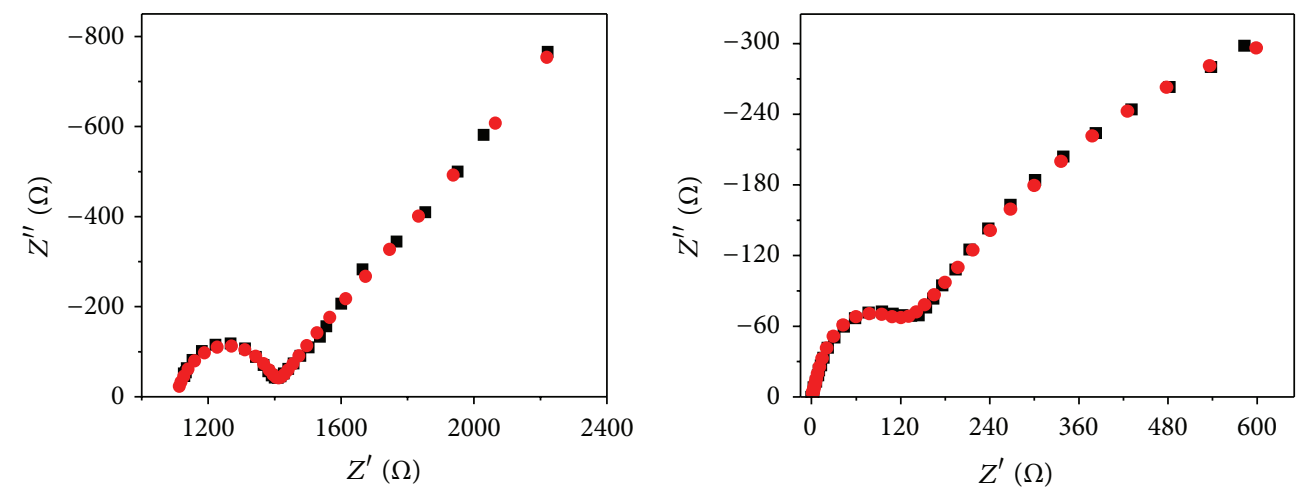

- NDC-4

- Fitted data

- GC

- Fitted data

FIGURE 7: Electrochemical impedance spectroscopy of Polyaniline and different NDC materials, measurements have been performed at the formal potential of the $\left[\mathrm{Fe}(\mathrm{CN})_{6}\right]^{3-/ 4-}$ redox couple $(5 \mathrm{mM},+200 \mathrm{mV}$ versus $\mathrm{Ag} / \mathrm{AgCl} 3 \mathrm{M} \mathrm{KCl})$ in the frequency range of $5 \mathrm{~Hz}$ (final) to $40 \mathrm{kHz}$ (initial) with an amplitude of $5 \mathrm{mV}$.

reversibility. Both these (i.e., greatly enhanced peak current, almost double, and the negative shift in the anodic overpotential of $0.22 \mathrm{~V}$ ) indicate strong electrocatalytic activity of the NDC electrode with respect to ascorbic acid electrooxidation. A large decrease in the overpotential of the ascorbic acid could be considered as a kinetic effect facilitating a substantial increase in the electron transfer rate of ascorbic acid oxidation, which could in turn be attributed to the delocalization of lone pair of electrons of the heteroatom.

\section{Conclusions}

Nitrogen doped carbon has been prepared from polyaniline base that exhibits unique electrocatalytic activity for ascorbic acid oxidation. The $\mathrm{C} / \mathrm{N}$ ratio in this is found to increase with treatment duration as evidenced by elemental analysis. SEM analysis has confirmed that the surface morphology is preserved even after the carbonization process of PANI. The conditions assuring that the conversion of PANI molecular 


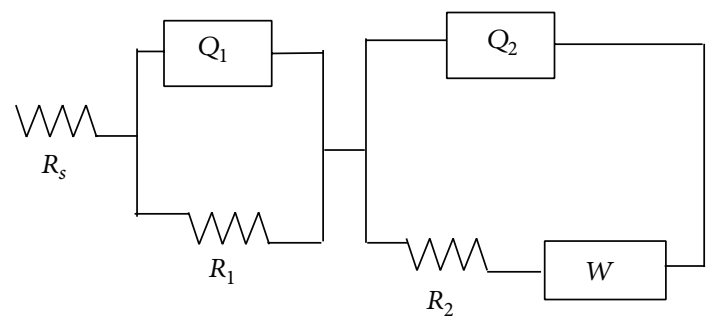

FIGURE 8: A schematic representation of the equivalent circuit used for fitting the data in this study.

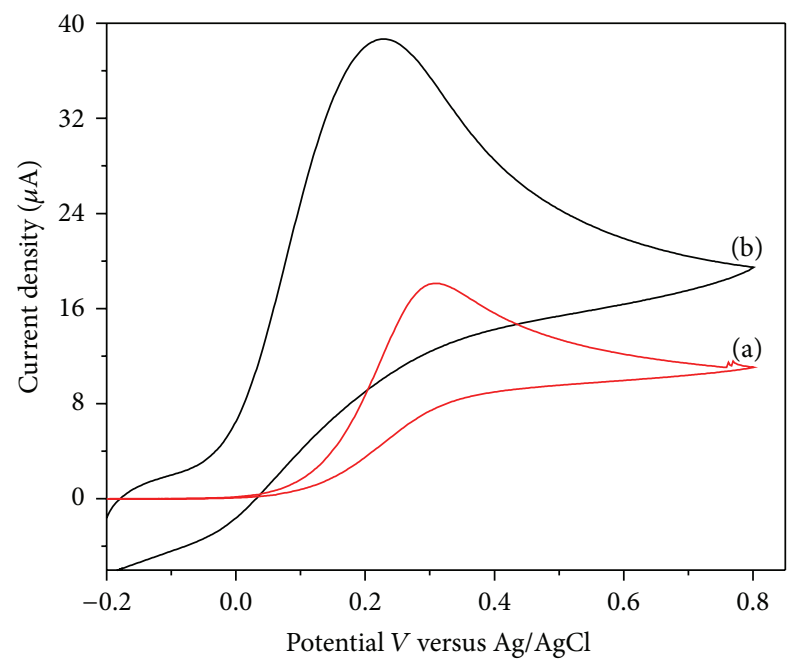

Figure 9: Cyclic voltammogram of $10 \mathrm{mM}$ ascorbic acid by using (a) Vulcan carbon paste electrodes and (b) NDC paste electrodes. Scan rate is $20 \mathrm{mVS}^{-1}$.

structure to the corresponding nitrogen-enriched carbon, while preserving a good yield, have been sought. The molecular structure and its changes, that is, polyaniline and carbonized PANI, are represented by disordered carbon-like material having different types of bonds between carbon and nitrogen atoms, as illustrated by phenazine-like crosslinked units, quinoid units, and so forth. Electrochemical characterization shows improved electrochemical activity for NDC compared to that on polyaniline or just heat treated (30 minutes) NDC. In a typical redox reaction, the $\Delta E_{\mathrm{p}}$ value has been observed as $100 \mathrm{mV}$ for the carbon material heat treated for 120 minutes. The impedance behaviour in the form of Nyquist plot shows a semicircle followed by a $45^{\circ}$ straight line behaviour (Warburg impedance) characteristic of diffusion followed by the charge transfer of the electroactive species at the electrode-electrolyte interface. Thus, the carbonized PANI, that is, nitrogen containing carbon, constitutes a novel material promising for several potential applications like biosensors and fuel cell electrocatalysts. This is especially true during the presence of nitrogen atoms in carbonized material having lone pair of electrons that undergoes delocalization. Further, the catalytic activity of the synthesized material has been demonstrated using ascorbic acid electrooxidation. Thus, the present nitrogen incorporated carbon opens new ways to tune chemical and electrochemical reactivity using in a legion of applications.

\section{Conflict of Interests}

The authors declare that there is no conflict of interests regarding the publication of this paper.

\section{Acknowledgment}

The authors gratefully acknowledge Dr. Vijayamohanan K Pillai, Director of CECRI, for his encouragement. The authors also acknowledge the financial support [DST/TSG/ PT/2009/82] from Department of Science \& Technology, New Delhi.

\section{References}

[1] R. L. McCreery, "Advanced carbon electrode materials for molecular electrochemistry," Chemical Reviews, vol. 108, no. 7, pp. 2646-2687, 2008.

[2] D. R. Rolison, "Catalytic nanoarchitectures-the importance of nothing and the unimportance of periodicity," Science, vol. 299, no. 5613, pp. 1698-1701, 2003.

[3] F. Li, Q. Qian, F. Yan, and G. Yuan, "Nitrogen-doped porous carbon microspherules as supports for preparing monodisperse nickel nanoparticles," Carbon, vol. 44, no. 1, pp. 128-132, 2006.

[4] M. Endo, C. Kim, T. Karaki et al., "Anode performance of a Li ion battery based on graphitized and B-doped milled mesophase pitch-based carbon fibers," Carbon, vol. 37, no. 4, pp. 561-568, 1999.

[5] Y. P. Wu, S. Fang, Y. Jiang, and R. Holze, "Effects of doped sulfur on electrochemical performance of carbon anode," Journal of Power Sources, vol. 108, no. 1-2, pp. 245-249, 2002.

[6] Y. Shao, J. Sui, G. Yin, and Y. Gao, "Nitrogen-doped carbon nanostructures and their composites as catalytic materials for proton exchange membrane fuel cell," Applied Catalysis B, vol. 79, no. 1, pp. 89-99, 2008.

[7] P. H. Matter, E. Wang, and U. S. Ozkan, "Preparation of nanostructured nitrogen-containing carbon catalysts for the oxygen reduction reaction from $\mathrm{SiO}_{2}-$ and $\mathrm{MgO}$-supported metal particles," Journal of Catalysis, vol. 243, no. 2, pp. 395-403, 2006.

[8] D. Deng, X. Pan, L. Yu et al., "Toward N-doped graphene via solvothermal synthesis," Chemistry of Materials, vol. 23, no. 5, pp. 1188-1193, 2011.

[9] S. Yang, X. Feng, X. Wang, and K. Müllen, "Graphene-based carbon nitride nanosheets as efficient metal-free electrocatalysts for oxygen reduction reactions," Angewandte Chemie International Edition, vol. 50, no. 23, pp. 5339-5343, 2011.

[10] S. Ma, G. A. Goenaga, A. V. Call, and D.-J. Liu, "Cobalt imidazolate framework as precursor for oxygen reduction reaction electrocatalysts," Chemistry: A European Journal, vol. 17, no. 7, pp. 2063-2067, 2011.

[11] D. Geng, Y. Chen, Y. Chen et al., "High oxygen-reduction activity and durability of nitrogen-doped graphene," Energy and Environmental Science, vol. 4, no. 3, pp. 760-764, 2011.

[12] Y. Xia and R. Mokaya, "Generalized and facile synthesis approach to $\mathrm{N}$-doped highly graphitic mesoporous carbon materials," Chemistry of Materials, vol. 17, no. 6, pp. 1553-1560, 2005. 
[13] A. B. Fuertes and T. A. Centeno, "Mesoporous carbons with graphitic structures fabricated by using porous silica materials as templates and iron-impregnated polypyrrole as precursor," Journal of Materials Chemistry, vol. 15, no. 10, pp. 1079-1083, 2005.

[14] C.-M. Yang, C. Weidenthaler, B. Spliethoff, M. Mayanna, and F. Schüth, "Facile template synthesis of ordered mesoporous carbon with polypyrrole as carbon precursor," Chemistry of Materials, vol. 17, no. 2, pp. 355-358, 2005.

[15] A. Lu, A. Kiefer, W. Schmidt, and F. Schüth, "Synthesis of polyacrylonitrile-based ordered mesoporous carbon with tunable pore structures," Chemistry of Materials, vol. 16, no. 1, pp. 100-103, 2004.

[16] M. Kruk, K. M. Kohlhaas, B. Dufour et al., "Partially graphitic, high-surface-area mesoporous carbons from polyacrylonitrile templated by ordered and disordered mesoporous silicas," Microporous and Mesoporous Materials, vol. 102, no. 1-3, pp. 178-187, 2007.

[17] W. Li, D. Chen, Z. Li et al., "Nitrogen-containing carbon spheres with very large uniform mesopores: the superior electrode materials for EDLC in organic electrolyte," Carbon, vol. 45, no. 9, pp. 1757-1763, 2007.

[18] C. Jeyabharathi, P. Venkateshkumar, M. S. Rao, J. Mathiyarasu, and K. L. N. Phani, "Nitrogen-doped carbon black as methanol tolerant electrocatalyst for oxygen reduction reaction in direct methanol fuel cells," Electrochimica Acta, vol. 74, pp. 171-175, 2012.

[19] L. Li, E. Liu, J. Li et al., "A doped activated carbon prepared from polyaniline for high performance supercapacitors," Journal of Power Sources, vol. 195, no. 5, pp. 1516-1521, 2010.

[20] Z. Lei, M. Zhao, L. Dang et al., "Structural evolution and electrocatalytic application of nitrogen-doped carbon shells synthesized by pyrolysis of near-monodisperse polyaniline nanospheres," Journal of Materials Chemistry, vol. 19, no. 33, pp. 5985-5995, 2009.

[21] M. Trchová, E. N. Konyushenko, J. Stejskal, J. Kovářová, and G. Ćirić-Marjanović, "The conversion of polyaniline nanotubesto nitrogen-containing carbon nanotubes and their comparison with multi-walled carbon nanotubes," Polymer Degradation and Stability, vol. 94, no. 6, pp. 929-938, 2009.

[22] J. Stejskal and R. G. Gilbert, "Polyaniline. Preparation of a conducting polymer (IUPAC technical report)," Pure and Applied Chemistry, vol. 74, no. 5, pp. 857-867, 2002.

[23] B. Sreedhar, P. Radhika, B. Neelima, N. Hebalkar, and M. V. B. Rao, "Synthesis and characterization of polyaniline: nanospheres, nanorods, and nanotubes-catalytic application for sulfoxidation reactions," Polymers for Advanced Technologies, vol. 20, no. 12, pp. 950-958, 2009.

[24] M. Trchová, P. Matějka, J. Brodinová, A. Kalendová, J. Prokeš, and J. Stejskal, "Structural and conductivity changes during the pyrolysis of polyaniline base," Polymer Degradation and Stability, vol. 91, no. 1, pp. 114-121, 2006.

[25] J. Stejskal, M. Trchová, and I. Sapurina, "Flame-retardant effect of polyaniline coating deposited on cellulose fibers," Journal of Applied Polymer Science, vol. 98, no. 6, pp. 2347-2354, 2005.

[26] J. Stejskal, M. Trchová, J. Brodinová, and I. Sapurina, "Flame retardancy afforded by polyaniline deposited on wood," Journal of Applied Polymer Science, vol. 103, no. 1, pp. 24-30, 2007.

[27] X. Zhang and S. K. Manohar, "Microwave synthesis of nanocarbons from conducting polymers," Chemical Communications, no. 23, pp. 2477-2479, 2006.
[28] Z. Rozlívková, M. Trchová, M. Exnerová, and J. Stejskal, “The carbonization of granular polyaniline to produce nitrogencontaining carbon," Synthetic Metals, vol. 161, no. 11-12, pp. 11221129, 2011.

[29] J. Stejskal, M. Trchová, J. Hromádková, J. Kovářová, and A. Kalendová, "The carbonization of colloidal polyaniline nanoparticles to nitrogen-containing carbon analogues," Polymer International, vol. 59, no. 7, pp. 875-878, 2010.

[30] J. Cao, J.-Z. Sun, J. Hong, H.-Y. Li, H.-Z. Chen, and M. Wang, "Carbon nanotube/CdS core-shell nanowires prepared by a simple room-temperature chemical reduction method," Advanced Materials, vol. 16, no. 1, pp. 84-87, 2004.

[31] M. I. Boyer, S. Quillard, G. Louarn, G. Froyer, and S. Lefrant, "Vibrational study of the $\mathrm{FeCl}_{3}$-doped dimer of polyaniline; a good model compound of emeraldine salt," Journal of Physical Chemistry B, vol. 104, no. 38, pp. 8952-8961, 2000.

[32] M. Cochet, G. Louarn, S. Quillard, J. P. Buisson, and S. Lefrant, "Theoretical and experimental vibrational study of emeraldine in salt form part II," Journal of Raman Spectroscopy, vol. 31, no. 12,, pp. 1041-1049, 2000.

[33] S. Y. Chee and M. Pumera, "Metal-based impurities in graphenes: application for electroanalysis," Analyst, vol. 137, no. 9, pp. 2039-2041, 2012.

[34] G. Socrate, Infrared and Raman Characteristic Group Frequencies, Wiley, 2001.

[35] L. Niu, Q. Li, F. Wei, X. Chen, and H. Wang, "Electrochemical impedance and morphological characterization of platinummodified polyaniline film electrodes and their electrocatalytic activity for methanol oxidation," Journal of Electroanalytical Chemistry, vol. 544, pp. 121-128, 2003.

[36] G. Wu and B.-Q. Xu, "Carbon nanotube supported Pt electrodes for methanol oxidation: a comparison between multi- and single-walled carbon nanotubes," Journal of Power Sources, vol. 174, no. 1, pp. 148-158, 2007.

[37] K. S. Ngai, W. T. Tan, Z. Zainal, R. B. M. Zawawi, and M. Zidan, "Electrochemical oxidation of ascorbic acid mediated by single-walled carbon nanotube/tungsten oxide nanoparticles modified glassy carbon electrode," International Journal of Electrochemical Science, vol. 7, no. 5, pp. 4210-4222, 2012.

[38] J. B. Raoof, R. Ojani, H. Beitollahi, and R. Hossienzadeh, "Electrocatalytic determination of ascorbic acid at the surface of 2,7-bis(ferrocenyl ethyl)fluoren-9-one modified carbon paste electrode," Electroanalysis, vol. 18, no. 12, pp. 1193-1201, 2006.

[39] S. A. Wring, J. P. Hart, and B. J. Birch, "Voltammetric behaviour of ascorbic acid at a graphite-epoxy composite electrode chemically modified with cobalt phthalocyanine and its amperometric determination in multivitamin preparations," Analytica Chimica Acta, vol. 229, no. 1, pp. 63-70, 1990. 

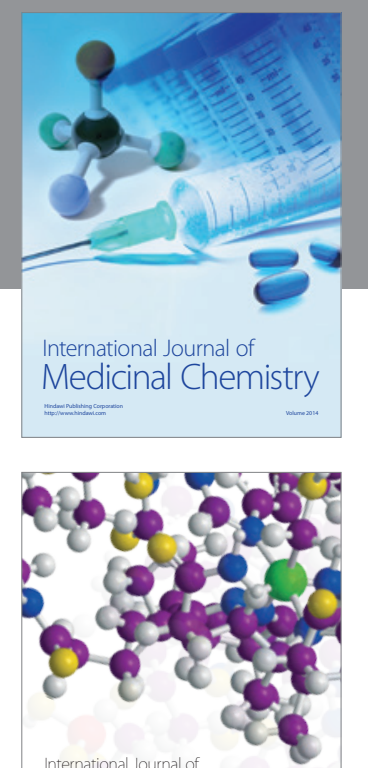

\section{Carbohydrate} Chemistry

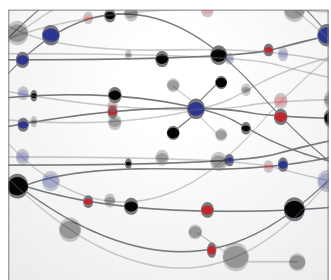

The Scientific World Journal
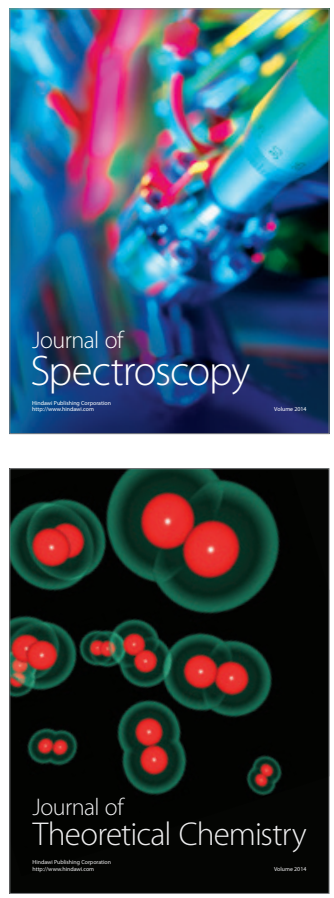
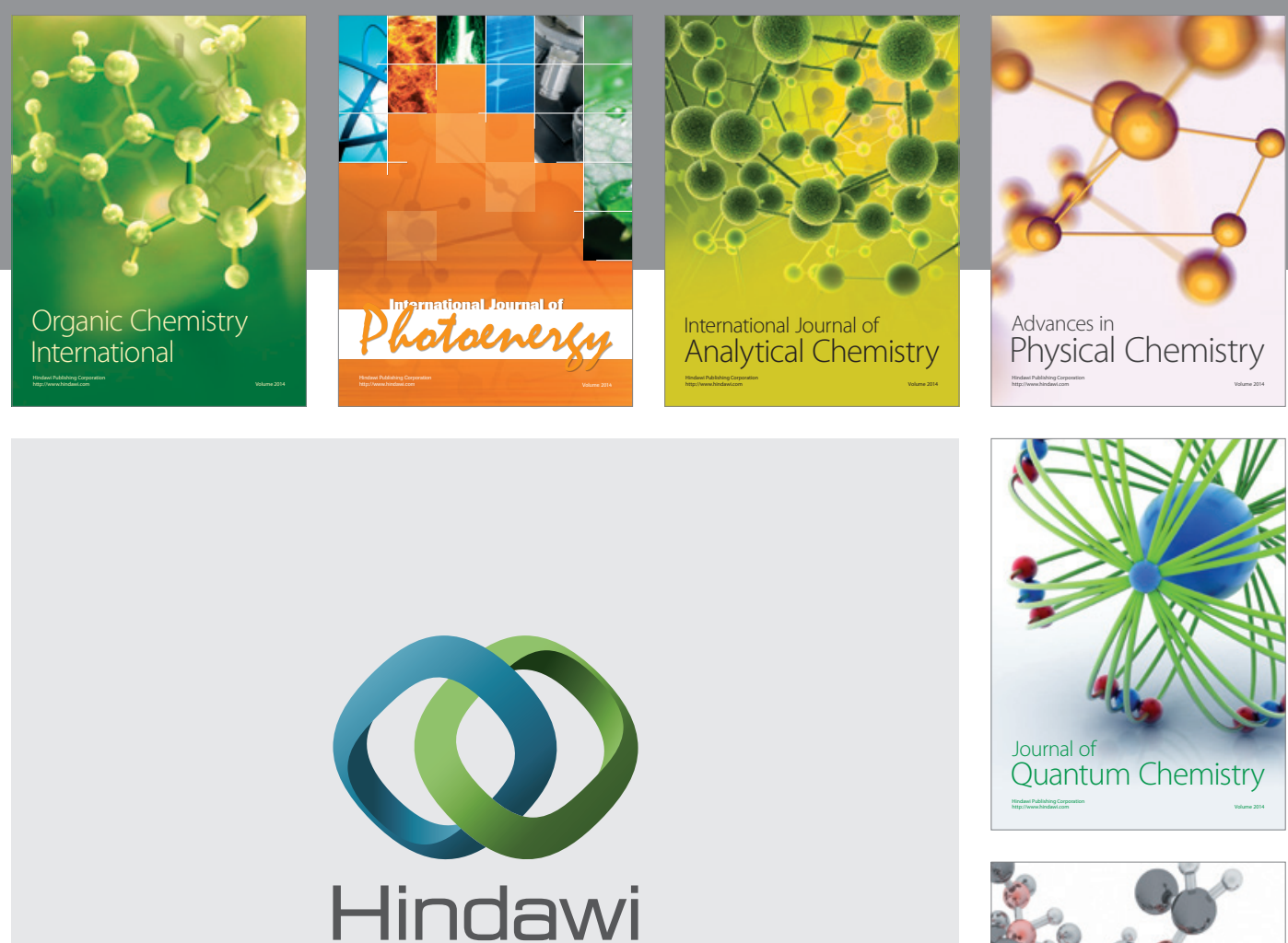

Submit your manuscripts at

http://www.hindawi.com

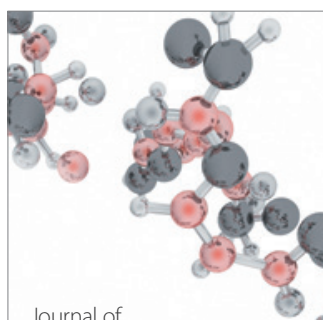

Analytical Methods

in Chemistry

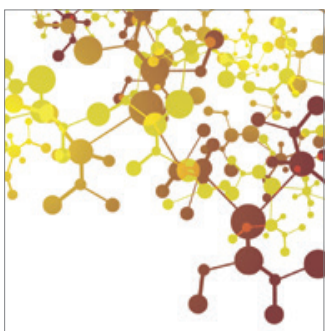

Journal of

Applied Chemistry

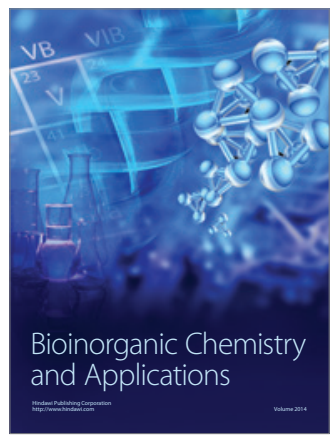

Inorganic Chemistry
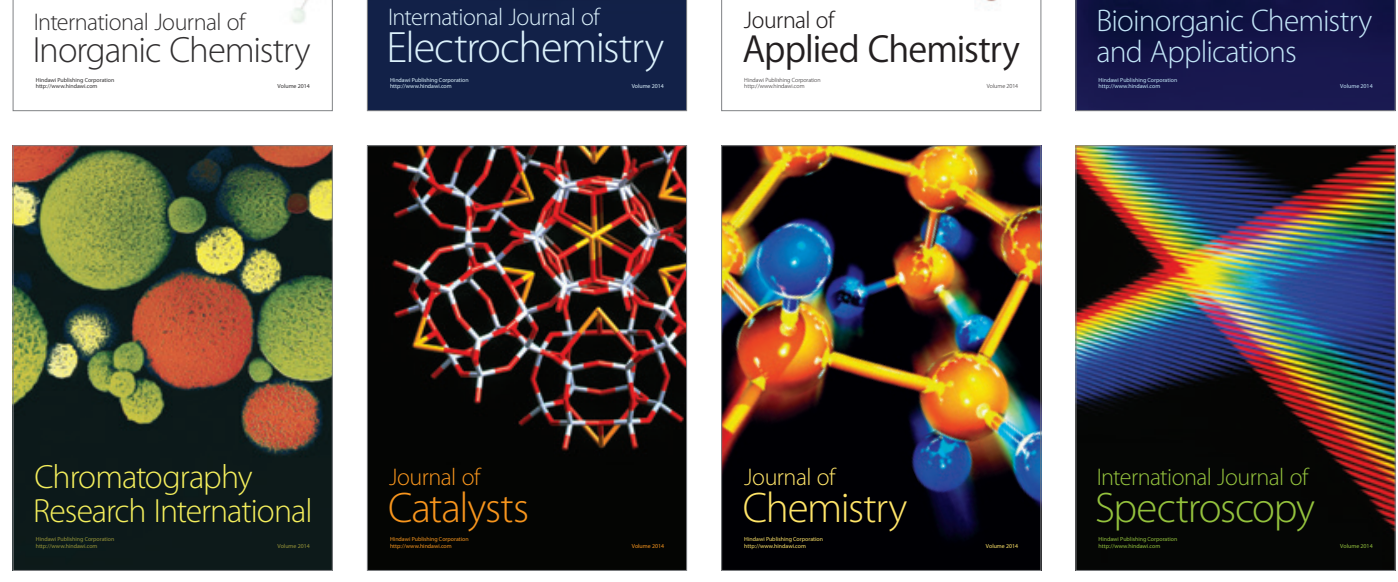